\title{
El teórico nómada*
}

\author{
Paul A. Harris ** \\ Traducción del francés al español de Luis Alfonso Paláu-Castaño \\ Universidad Nacional de Colombia, sede Medellín, Colombia \\ lapalau@gmail.com
}

Ya no es incomprensible que el mundo sea comprensible.

El intercambio, como ley del universo teórico, el transporte de conceptos y su complicación, la intersección y el recubrimiento de dominios, la conferencia indefinida del sentido en la especulación no referenciada, imitan desde entonces, representan, expresan, reproducen, qué se yo, el tejido mismo donde están sumergidos los objetos, que son las cosas mismas, la red mundial diabólicamente compleja de la entre-información.

\section{La teoría al borde del abismo}

Gracias a la naturaleza perpetuamente móvil de su pensamiento, Michel Serres puede ser calificado de teórico nómada. Serres se ha interesado en dominios muy diversos: biología molecular y ciencia ficción, topología y pintura, lingüística y antropología. Su obra es un viaje de la Grecia antigua hasta el lanzamiento del transbordador Challenger, de las riberas inundadas del Nilo hasta el banco de hielo del Paso del Noroeste; él se ha aventurado por el fatal cruce de los caminos de Edipo y se ha hundido en las profundidades hirvientes del caos; ha sido parásito, navegante y cicerone, no cesa de cambiar de vestido. Este título de "teórico nómada" se lo debe también a la multiplicidad de los itinerarios teóricos que ha trazado y al hilo de los cuales busca tejer el saber sobre una trama que conecta al hombre y al mundo. Lo que ha dicho de la Odisea podría perfectamente aplicarse a sus propios escritos: "El vagar global, la aventura mítica no es a fin de cuentas, más que el empalme general. Como si el discurso solo tuviera por objeto o como blanco el conectar. O como si el enlace, la relación, constituyera la vía por donde pasa el primer discurso" (Serres, 1981, p. 34).

* Cómo citar: Harris, P. A. (2019). El teórico nómada. Ciencias Sociales y Educación, 8(16), 205-221. DOI: https:// doi.org/10.22395/csye.v8n16a14

Traducción realizada por Luis Alfonso Paláu-Castaño. Agradecemos la editorial L'Herne permitir el acceso del libro en francés para su versión, en partes, en español.

Recibido: 10 de agosto de 2019.

Aprobado: 20 de septiembre de 2019.

** Profesor de inglés, literatura y teoría, y de estudios interdisciplinarios en Loyola Marymount University (Los Angeles). Es co-editor de SubStance y Presidente de la International Society for the Study of Time. Ha publicado trabajos sobre Michel Serres, Deleuze, Lyotard y Bergson. Es igualmente editor de The Study of Time (Brill Academic Publishers). 
Como Ulises, Serres se adentra por una trayectoria sinuosa que lo conducirá quizás a la tierra que es la suya. Pero la destinación no es aquel hogar y el perro fiel. Serres aspira a una dimensión más vasta, más global que se podría llamar el nicho ecológico de la humanidad. En el fondo, los hombres pertenecen al mundo de una manera simple y esencial: "nada me distingue ontológicamente de un cristal, de una planta, de este animal y del orden del mundo" (Serres, 1977). Esta ontología converge con una visión según la cual el proceso, la inestabilidad y el desorden constituyen el estado primitivo de las cosas, en un universo que no deja de recordarnos las metamorfosis de Ovidio, donde los animales, los hombres, las cosas y las ideas se transforman sin cesar los unos en los otros. ¿Qué lugar ocupa Serres en este mundo? "Soy el trastorno, un torbellino en la naturaleza turbulenta" (Serres, 1994, p. 162). "¿Quién soy? Una tremulación de nada que vive en un seísmo permanente" (Serres, 2004, p. 190).

Si estas afirmaciones tienen valor retórico, así mismo son reveladoras del movimiento que anima el pensamiento de Serres: un deseo de disolver la diferencia entre el lenguaje y la representación, de fusionar el saber y el ser. Esta dimensión de la obra de Serres encuentra su formulación más explícita en El contrato natural, que culmina en la evocación del temblor de tierra de Loma Prieta en California en 1989. Serres (2004) confiesa haber "experimentado alegría durante el temblor de tierra que atemorizó a tanta gente a su alrededor. De repente el suelo sacudía sus aparatos: los muros se estremecían, dispuestos a hundirse desatados de su aparato; los techos se torcían, mujeres caían, las comunicaciones se interrumpen, el ruido impide que uno se oiga, la delgada película técnica se desgarra rechinando (...)". Parecía haber experimentado entonces un goce sublime, por no decir erótico: "la he visto [a la tierra], con mis ojos y con mi entendimiento hace poco; en fin, por mi vientre y mis pies, la veo por mi sexo" (pp. 190-191). Transportado fuera de su espíritu y sumergido por su propio cuerpo, Serres alcanzó el "éxtasis" en su conexión visceral con "el ruido de fondo, el mundo que brama".

\section{Naturaleza y saber / ecología e interdisciplinariedad}

El choque sublime que Serres testifica haber sentido en ese sismo abre una brecha en la retórica del saber. El suelo resquebrajado donde se entrechocan las placas tectónicas del Pacífico y de América del norte es el terreno de una nueva comprensión del mundo. Se podría decir que Serres invoca un saber íntimo y visceral de la naturaleza con el fin de redefinir la naturaleza misma del saber. En su reseña de El contrato natural, Malina Stefanovska (1992) hace notar que "en sus escritos, en lugar de colocarla como un objeto exterior, la naturaleza es percibida como una fuerza interior que acaba de romper el discurso y lo abre a una meditación poética vigilante" (pp. 163-164). La producción de un discurso 
es paradójica en tanto que hace aparecer la naturaleza en disposición de discurso, como si ella hubiera irrumpido en él. Esta paradoja remite a una tensión fundamental que atraviesa la escritura de Serres, que oscila entre el deseo de establecer un vínculo inmediato con el mundo y el proyecto de elaborar un discurso enciclopédico que restituya nuestra relación con el mundo. Pero dado que el saber institucionalizado tiende a la especialización y al aislamiento, la erudición misma que desmarca a Serres de sus contemporáneos es precisamente lo que amenaza con cavar la distancia entre el filósofo y el mundo.

Por ejemplo, su concepción del saber en tanto que tal, más allá de la simple extensión de su erudición ocupa un lugar central en su obra. Para Serres, el saber no descansa sobre alguna cosa; no es del orden de la representación o de la crítica. El filósofo tal como Serres lo encarna, no puede quedarse en una ontología o a una epistemología; construye también una ecología en la que las cosas interactúan. Al hilo de sus itinerarios, como la araña que teje su tela, Serres procede al "transporte de conceptos" cuya "intersección y recubrimiento" hacen parte integral del "tejido mismo donde están inmersos los objetos". La tela como totalidad corresponde a lo que él llama "la red mundial diabólicamente compleja de la entre-información". La escritura de Serres presenta así una trama bien legible; sus ensayos son retoños híbridos, cruces genéticos que ayustan lenguajes dispares.

Este método le permite a Serres practicar una forma de interdisciplinariedad bien particular. En vez de crear "interfaces" entre dominios estáticos, él los imbrica los unos en los otros, revelando sus analogías morfológicas ocultas y disponiendo pasajes puntuales del uno al otro ${ }^{1}$. Logra así modelar el saber disciplinario en un campo flexible, una epistemología enciclopédica donde se entrega a operaciones de azar y de invención. Serres habla casi literalmente cuando afirma que "el saber como tal es un espacio de transformación"2. Él ha designado igualmente a este espacio como "tercero instruido", umbral o frontera por franquear, zona de tránsito ${ }^{3}$ (Serres, 1997, p. 13). Su método por su flexibilidad y movilidad, abre una perspectiva transdisciplinaria cuyo alcance es esencialmente global.

1 Para una crítica de la metáfora de la "interfaz", ver las anotaciones de Serres in Paisley Livingston, Literary knowledge: Humanistic inquiry and the philosophy of science, Cornell University press, 1988, pp. 251-258. A propósito de los pasos interdisciplinarios, ver especialmente Hermes V, el Paso del noroeste. Madrid: Debate, 1991.

2 Michel Serres. Le Parasite. París: Grasset, 1980, p. 99.

3 El Tercero-instruido. Trad. por L. A: Paláu. para el seminario "Equilibrio \& Fundaciones", Medellín, Septiembre de 1997. p. 13. Para un acercamiento al entre-dos como operador conceptual para la interdisciplinariedad, ver Noelle Batt, “ 'L'Entre-Deux', A bridging concept for Literature, Philosophy and Science”, SubStance 74 (XXIII, $\left.\mathrm{n}^{\circ} 74,1994\right)$, pp. 38-48. 
La perspectiva global de Serres se expresa a través de las afirmaciones audaces que escanden sus escritos; en diversos textos él decreta que el lenguaje nace del ruido; que Zola descubrió la termodinámica; que la geometría nace de la violencia y lo sagrado. Para Serres, sin embargo, la "globalidad" no se aplica solamente al saber, sino también al sujeto y al objeto del saber; el teatro de su filosofía es el mundo entero. Estima que la teoría crítica descuidó la dimensión ecológica porque "nuestra cultura le tiene horror al mundo" (Serres, 2004, p. 16), ella privilegió el saber en detrimento del mundo natural. Pero a medida que los daños causados a la biosfera se manifiestan de forma más flagrante, la línea de demarcación entre naturaleza y cultura se hace más huidiza. Al mismo tiempo, la biosfera penetra la noosfera, el campo del saber: "la historia global entra en la naturaleza; la naturaleza global entra en la historia; esto es lo inédito en filosofía" (Serres, 2004, p. 18).

Según la perspectiva global adoptada en El contrato natural, la naturaleza del saber evoluciona a medida que la naturaleza de la naturaleza atraviesa una mutación radical. Las transformaciones más importantes a las que está sometida la ecología planetaria conducen una interacción de las ideas y la biosfera. "Bruscamente, un objeto local, la naturaleza sobre la cual un sujeto solamente podía actuar de forma parcial, se vuelve un objeto-global, el planeta tierra sobre el cual un nuevo sujeto total, la humanidad, se atarea" (Serres, 2004, p. 19). En la ecología global, la metamorfosis (fuerza dinámica que engendraría nuevos organismos) interviene de acá en adelante a nivel de la especie. El hombre ya no está "sepultado como un punto sin dimensión; existe como conjunto, supera lo local para extenderse a inmensas placas" (Serres, 2004, p. 37). "Henos llegados a tamaños tales que existimos físicamente. Devenido animal en común, el individuo que piensa, múltiplemente asociado se transforma en piedra (...). Existimos por fin naturalmente. El espíritu ha crecido en animal, y el animal aumenta en placa (tectónica)" (Serres, 2004, pp. 39-40). Serres esboza una nueva concepción de la humanidad como cuerpo geopolítico, donde lo "geopolítico" no se define por la geografía sino por la geología. El desplazamiento de metáfora destituye la humanidad como sujeto de la historia que se imponía sobre el mundo; de acá en adelante la especie es una fuerza de la naturaleza, y sus erupciones cambian el curso de la historia global tanto natural como cultural. En esta cartografía, los territorios topológicamente discretos de la geografía de superficie dan paso a estratos topológicos fisurados por los temblores de tierra. (La cartografía topológica, como lo veremos, ocupa un lugar central en el modelo ecológico de Serres).

Esta evolución de la humanidad hacia una dimensión global convoca una nueva relación del hombre con el entorno. El contrato social sobre el cual reposa una parte tan amplia de nuestra cultura occidental, debe ser reemplazada por lo que Serres llama el "contrato natural". La noción de contrato natural elabo- 
rada por Serres se inscribe en la prolongación de sus trabajos sobre Lucrecio y la filosofía epicúrea, que lanzan una pasarela entre contrato social y contexto natural. En El nacimiento de la física en el texto de Lucrecio, Serres (1994) coloca la premisa que mantiene la tesis epicúrea: las leyes sociales y la escritura derivan de las leyes naturales porque "la historia es una física y no lo inverso. El lenguaje está ante todo en los cuerpos" (p. 186). Esta interpenetración de la semiótica y la materia constituye una extrapolación literal de la visión lucreciana que comparaba los átomos con las letras: "que los átomos sean letras, que los cuerpos conectados sean frases, no es sin duda una metáfora; es aquello sin lo cual no habría existencia" (Serres, 1994, p. 185).

La referencia al modelo lucreciano tiene que ver con que él se fundamenta en una libertad esencial. En esta cosmología, evolución cultural y natural se presentan como procesos de transformación perpetua; sobrevienen mutaciones imprevisibles porque no hay "leyes" globales ni completamente deterministas. "La naturaleza no codifica lo universal", escribe Serres; es el clinamen, la desviación imprevisible, la que desvía los átomos de su recorrido determinado e introduce el cambio. El clinamen despliega el tejido del mundo, "efectúa la primera codificación, introduce un tiempo nuevo, lo escrito, la memoria, lo reversible y la neguentropía" (Serres, 1994, p. 186).

\section{Contrato cultural}

El clinamen es una ley física que condiciona la noosfera, la biosfera y la atmósfera, y repercute a través de ellas. Está en la base de una filosofía anti-determinista del libre arbitrio y sirve de garante a la contingencia, la novedad y la diferencia. En una lectura transversal que le es propia, Serres aborda el poema de Lucrecio como un tratado de física que anuncia una "ciencia creativa del azar y de las circunstancias" que "rompe la cadena de la violencia, interrumpe el reino de lo mismo", propio del ethos de la ciencia moderna (Serres, 1994, pp. 136-137). Lucrecio se apoya en la física para explicar y justificar el lugar del hombre en el mundo. La física del clinamen describe un mundo fluido y dinámico en el cual el "individuo" o el "sistema" es percibido como una manifestación temporal del orden que emerge de un caos generalizado. Así mismo, en El contrato natural Serres (2004) busca una "ciencia fuerte y simple" que le "dictará el momento del desenlace, del desnudamiento del verdadero levantar anclas, y de no tomar nada para ir completamente desnudo (...) de esta tierra hacia la nada" (p. 177).

Esta ciencia solo se puede desarrollar con la condición de repensar las estructuras institucionales. Una vez más, Serres integra problemáticas éticas y pedagógicas en un laboratorio de invención interdisciplinaria ${ }^{4}$. Él diagnostica

Para reflexiones más explícitas sobre problemáticas pedagógicas, ver "Literature and the exact science", SubStancia 59. Serres (1989). 
las "patologías culturales" inherentes a la organización del saber, que trazan líneas de poder y atormentan el deseo en un gesto destructor. A sus ojos, las prácticas educativas que prevalecen en Occidente son informadas por la "finitud estrecha de una instrucción que produce especialistas obedientes o ignorantes llenos de arrogancia", que deja a los espíritus presa de "la infinitud del deseo, drogando a muerte pequeñas larvas blandas"5. Para Serres, una ciencia que nos permita desprendernos de la obligación debe también estar fundamentada en la acepción de la finitud de nuestro ser y nuestro ecosistema.

Para respetar el "contrato natural" es preciso que el saber opere en muchos niveles y se encaje en diversos contextos. Serres también describe el contrato natural como una cuerda que mezcla tres hilos: definición de un dominio o de un objeto de estudio; relación con el sujeto; lazo intersubjetivo. En esta triple cuerda, el contrato natural trenza los conceptos, los discursos y los dominios que han ocupado siempre un sitio central en su obra:

Usos formal, energético e informativo, si se prefiere conceptual, material y jurídico; geométrico, físico y de derecho. Lazo de conocimiento, de potencia y de complejidad. En suma, su triple trenza me une a las formas, a las cosas, a los otros, me inicia en la abstracción, al mundo, a la sociedad (Serres, 2004, p. 177).

El contrato natural nos implica en un conjunto complejo de prácticas entremezcladas, que reposa sobre una conciencia aguda de los vínculos entre acción local, historia global y biosfera. Esta concepción del contrato natural no convoca a un simple regreso a la naturaleza, sino que abre la vía a un nuevo discurso ecológico que complica el binomio naturaleza/cultura, considerando los sistemas naturales como imbricados en formaciones culturales, y las categorías sociales como orilladas por categorías orgánicas.

\section{Topología}

Hemos visto que el fundamento conceptual del discurso ecológico e interdisciplinario de Michel Serres, se sostenía en la comodidad de sus idas y regresos entre lo local y lo global. Se podría decir que Serres entabla una retórica de lo local en una red de conexiones globales. Manejando una retórica propicia al caos y la contingencia, lo local y circunstancial, Serres establece por otra parte analogías entre disciplinas muy heterogéneas al plan global, conceptual, mostrando que un conjunto isomorfo de relaciones estructurales persiste en o entre dos discursos diferentes. Conviene leer a Serres en términos de "espacio" donde se despliegan los itinerarios de su obra. Este espacio presenta seguramente algunas propiedades: concilia la contingencia local y la coherencia global; no se trata de una topografía fija compuesta de muchas regiones (o disciplinas), sino

\footnotetext{
5 Para una comparación, ver Gregory Bateson (1991; 1997) sobre las patologías culturales.
} 
de una superficie maleable susceptible de estirarse y replegarse (los discursos se mezclan constantemente los unos con los otros). Serres trabaja a la vez en y sobre este tipo de espacio, que no solamente informa todos sus escritos, sino que es el objeto de una teorización explícita.

A nivel global, la obra de Serres ha salido del encuentro con el estructuralismo, no lingüístico o antropológico sino matemático. El concepto de estructura elaborado por Serres está inspirado en los trabajos de Bourbaki, ese colectivo de matemáticos que buscó sistematizar las matemáticas en relaciones sintácticas abstractas. En el primer volumen de "Hermes", Serres (1993) define la estructura como "un conjunto operacional con significación indefinida (...), que agrupa elementos en un número cualquiera, del que no se especifica el contenido, y relaciones en número finito de las que no se especifica la naturaleza, pero de los que se define la función y algunos resultados en cuanto a los elementos". No es necesario conocer el contenido ni la naturaleza de los elementos, solamente las relaciones entre ellos. Serres también puede afirmar: "solo describo relaciones. Hasta ahora contentémonos con decir teoría general de las relaciones" (Serres y Latour, 2010, p. 93).

El discurso que permite cartografiar un espacio generalizado de relaciones es la topología. Este "espacio" recubre las relaciones y configuraciones en la esfera de la naturaleza, del discurso y la cultura. La topología se pliega a estas adaptaciones porque dispone de un vocabulario flexible y bastante abstracto de relaciones y transformaciones. Esta disciplina trata de las propiedades del espacio que permanecen constantes; ella estudia las fronteras de las configuraciones espaciales: “¿Qué es un espacio abierto? ¿Qué es un camino de conexión? ¿Qué es un desgarrón? ¿Qué es lo continuo y lo discontinuo? ¿Qué es un umbral, un límite?" (Serres, 1981, p. 28). La naturaleza conceptual de la topología concibe el "espacio" como flexible y maleable, más bien que rígido e inmutable. Serres considera que hay que distinguir la topología, "ciencia de los vecindarios y de las desgarraduras", de la geometría métrica, "ciencia de las distancias bien definidas y estables" (Serres y Latour, 2010, pp. 44-45). La topología ofrece así una sintaxis y un léxico capaz de representar las relaciones abstractas entre los términos en los nudos y las lanzaderas de la "red de la entre-información".

Desde que el lenguaje se concibe como una red, su espacio puede descifrarse en términos de topología. Para retomar un axioma central y particularmente fecundo del ensayo sobre Lucrecio, "la semiótica es ante todo una topología" (Serres, 1994, p. 179). En lingüística las relaciones topológicas se expresan esencialmente por medio de las preposiciones. La topología en general y las preposiciones en particular remiten a los modos de enlace y son inherentes a la representación del entre-dos. Para describir los espacios más intrincados, "hay que utilizar con circunspección el entre, en, por (...) Operadores de flexiones o 
de declinaciones que designan no los lugares como tales, (...) Sino las relaciones de vecindad, de proximidad, de alejamiento, de adherencia o de acumulación, es decir: las posiciones" (Serres, 1995, p. 69).

La topología hace parte integral de la ecología cultural de Serres en la medida que ella informa su noción de cultura. Ella conduce a conceptualizar las ecologías como redes de relaciones, tejido u ola de conexiones entre diferentes espacios en un contexto dado: "una cultura en general construye en su historia y a través de ella, una intersección original entre tales variedades, un nudo de conexiones muy preciso y particular" (Serres, 1981, p. 29). La topología elucida las fronteras y los límites constitutivos de la cultura, actuando para ello como un sistema de constreñimientos sobre las formas admisibles. La interdicción del incesto, por ejemplo, puede formularse en términos de distinción, central en topología, entre espacio abierto y espacio cerrado: "encerradas, aisladas, cerradas, separadas; encerradas, no manchadas, puras y castas, por ejemplo. Ahora bien, lo que no es casto, incestus, puede ser el incesto. La interdicción del incesto es entonces, literalmente una singularidad local ejemplar de esta operación en general. Trabajo global de conectar lo desconectado o a la inversa, de abrir los cerrados" (Serres, 1981, pp. 29-30).

\section{Operadores textuales}

La obra de Serres, definida por una ecología del saber cartografiada por métodos topológicos, nos incita a redescubrir y reinventar la función de materiales familiares. Los textos literarios se vuelven entonces dinámicos. Ya no están anclados en la representación o reducidos a problemas lingüísticos, sino que se presentan como configuraciones complejas de información y energía. Sirven de acá en adelante de "operadores", de nudos que acercan muchas dimensiones de la vida, de los dominios de experiencia y de saber. Visto a través del prisma de Serres, el discurso de la ficción ya no es solamente semio o psico lógico, sino topo-lógico y eco-lógico; expresa la lógica del topos, lugar, y del oikos, hogar. La ficción se forja un lugar en el mundo.

Este método nos permite pasar de "lo interno" del texto a su inscripción en una red más amplia de relaciones. El enfoque topológico "interno" del texto identifica los esquemas que funcionan en sus diferentes niveles y los conectan entre sí; la topología suscita homologías entre las figuras, el estilo, la forma y el tema de una obra; muestra cómo esos esquemas se reproducen en las categorías frecuentemente inertes del decorado y la intriga. En otros términos, Serres nos enseña a desalojar los principios autopoiéticos que sostienen un texto. ¿En qué la dinámica métrica, metafórica y formal presenta autosimilitudes? La dificultad que plantea la lectura o la interpretación de Serres no busca demostrar esquemas estructurales isomorfos presentes en diferentes niveles textuales. Ante todo, los 
presupone desde el comienzo y hace de ellos los primeros "operadores" del texto. Desde que un operador textual se adelanta, él puede desplazarse dentro del texto o hacerlo jugar con otros campos discursivos. De una manera general, un operador es aquí un concepto o un tropo que abre pasajes y transcodificaciones interdisciplinarias. Los operadores pueden desplazarse en todos los sentidos dentro de un discurso o traspasar fronteras. Los términos y los conceptos matemáticos y científicos también tienen función de operadores: "[la historia de las ciencias] ofrece menos interés como objeto o como campo, que como conjunto de operadores, método o estrategia que operan en formaciones diferentes de ella" (Serres, 1981, pp. 23-24).

Dado que Serres no privilegia ninguna disciplina en particular, se sirve de operadores para efectuar idas y retornos entre ciencias naturales y la literatura. ¿Cómo un término científico puede servir de operador en o sobre un texto o inversamente? ¿Cuál es la física que opera en un texto? Uno de los principios ejes de análisis del De rerum natura consiste así en reconectar la física y la poética de Lucrecio; explicar "por qué este texto de física es un poema" proponiendo para ello una "aplicación de la física de las texturas al texto que lo enuncia" (Serres, 1994, p. 168). Para hacerlo, Serres recurre a muchas estrategias, en general a una lengua común a la física y a la poética por el sesgo de los juegos de lenguaje ("hacia/verso" y "pendiente de entablamento"), ora reproduciendo la espiral de los torbellinos en las imágenes del texto y en su forma general. Si ignoramos el propósito físico del poema, arriesgamos con volver a Lucrecio ajeno al mundo; en desquite una aproximación interdisciplinaria muestra cómo la poética, la física, la ética y la metafísica se entrecruzan y se hacen eco en el cuerpo del texto. Al entremezclarse las diferentes dimensiones o "espacios" de una obra, Serres muestra que la literatura entremezcla el tejido de la cultura, y sin recurrir a ninguna explicación teológica define el sitio de la humanidad en un orden natural. En el universo epicúreo de Lucrecio, "la ciencia de las cosas y la ciencia del hombre convienen en la identidad” (Serres, 1994, p. 162).

\section{Cruzamiento Serres/Melville/Olson}

Si se quiere permanecer fiel al método de Serres, es preciso no buscar "aplicar" su obra a un objeto. Se trata claramente de confrontarlo con otros trabajos. Serres mismo se vuelve un "operador" en un discurso hídrico cuya trama le debe tanto a su método como a sus tesis teóricas específicas. Con el fin de transponer a Serres al contexto de la literatura y la teoría norteamericanas, propondría una breve lectura de Moby-Dick de Melville a la luz de los elementos ecológicos y topológicos de su obra. Esta novela presenta muchos motivos que se prestan a un enfoque: superposición de los discursos, combinación de una visión social y de una filosofía natural, autosimilaridad de sus diferentes espacios, ya se 
trate de la descripción del océano o la cacería del cachalote, de los esquemas sintácticos o la concepción de las relaciones sociales. Por lo demás, tanto para Melville como para Serres la naturaleza se resiste al análisis; Melville piensa igualmente representar la naturaleza como una fuerza interior que hace irrupción del exterior. Finalmente, y en términos más abstractos, el "espacio" de Moby-Dick (tanto textual como geográfico) remite a una topología del continuo.

La obra de Melville ha sido analizada en términos topológicos por Charles Olson, figura de la literatura estadounidense que presenta singulares afinidades con Michel Serres. Como este último, Olson busca un saber verdaderamente interdisciplinario. A propósito de su práctica pedagógica indisciplinada, en el marco de la Black Moutain School, afirma: "si no hay muros, no hay nombres (...), y nuestro deber es entonces metodológico. Cómo y a qué dedicarnos" (Olson, 1974, p. 40). Los estudios que Olson consagró a Melville le hacen eco a la obra de Serres. Olson igualmente extrae de muchos dominios para elaborar modelos conceptuales que vienen a desplegarse en todas sus implicaciones culturales.

El uno como el otro, Olson y Serres, encuentran en las matemáticas de fines del siglo XIX un discurso del continuo que expresa una nueva relación entre el sujeto, el espacio y el mundo. En la prolongación de Lobatschevsky y de Riemann, Olson propone una visión del espacio donde "nada es un hecho inerte; todo está ahí para aguzar la sensación y ser experimentado; el hombre en medio de todo esto, consciente de estar implicado en ello y de poderse desplegar (...), de repente es investido o reinvestido de su ser, una cosa entre las cosas, que yo califico de fisicalidad" (Olson, 1966, pp. 47-48). Esta noción de fisicalidad implicada en el hombre es fiel al proyecto lucreciano de un retorno a la naturaleza. Serres encuentra en Lucrecio una concepción de la humanidad como torbellino temporal que emerge a contracorriente del flujo temporal neguentrópico: "soy la perturbación, un torbellino en la naturaleza turbulenta", nos dice Serres, "mis arrugas en la frente son las mismas del agua" (p. 162).

El espacio continuo y fluido en que se inscriben Moby-Dick y la obra de Serres, resiste nuestros hábitos cartesianos, aplicados a un mundo de objetos discretos y de campos bien delimitados. Los campos discursivos de Melville y Serres remiten a otra física. Olson (1966) se interroga sobre la diferencia que hay que trabajar en un mundo donde la topología es del continuo: "¿Qué es la medida cuando el universo descarrila y que ninguna de sus partes es discreta, sino que está en el flujo de creación, pasando del adentro al afuera, de lo cualitativo a lo intensivo, de lo extensivo a lo más amplio que tenemos también los poderes de incluir?" (p. 48). ¿Cómo entran las cosas en relación en un universo donde no hay impacto entre dos cuerpos sólidos, ninguna demarcación clara entre unidades discretas? ¿Qué significan los términos "acción" y "fisicalidad" 
tal y como los utiliza Olson en un campo continuo de energías? Y en otro nivel, ¿qué género de discurso expresa o encarna ese mundo?

Las incursiones de Melville en la cetología (a menudo desdeñadas por los críticos que no las consideran como literarias) se revelan aquí decisivas, en tanto que convocan una física del continuo. Ciertamente, el conjunto del relato subraya los límites de la ciencia natural como forma de saber. Ismael nos recuerda constantemente que el misterio del cachalote escapa a este discurso. Sin embargo, así como Lucrecio se servía del atomismo epicúreo para fundamentar la ética, los capítulos cetológicos de Melville plantean los fundamentos físicos de una metafísica del cachalote. La cetología de Melville excede en efecto el saber científico natural. Ismael avanza hacia una teoría topológica de uno de los elementos más misteriosos del cachalote: la composición interna de su frente. La topología es a menudo percibida como una geometría plástica, que consiste en estirar y replegar las superficies. En topología, las fronteras entre interior y exterior, contenido y continente siempre son reversible y móviles. Al describir la frente del cachalote, Melville formula una tesis notable sobre el contacto permanente entre el adentro y el afuera: al considerar la manera por lo demás inexplicable, en que unas veces sumerge por completo la cabeza bajo la superficie y otras veces nada llevándola elevada por encima del agua, considerando la elasticidad sin obstáculos de su envoltorio, digo por vía de hipótesis, que esos misteriosos panales de celdillas pulmonares que hay en su cabeza puedan quizá tener alguna conexión hasta ahora desconocida e insospechada con el aire exterior, de tal modo que sean capaces de distensión y contracción atmosférica. Si es así, imaginaos lo irresistible de esa fuerza a que contribuye el más impalpable y destructor de todos los elementos (Melville, 1987, pp. 37-38).

El imponente "acorazado" revela ser una membrana permeable, una superficie topológicamente continua que conecta lo interno con lo externo a la manera de una cinta de Möbius. El movimiento alternado de la cabeza por encima y por debajo del agua es reproducido por el ritmo mismo de las frases, mientras que la imagen y el estilo imitan la "dilatación" y la "contracción" de los pulmones y los elementos. La interioridad compleja de los pulmones se vuelve una extensión replegada de la atmósfera ambiente. En la cetología de Melville la frontera entre saber científico y especulación filosófica se diluye.

La cita que acabamos de hacer presenta igualmente el escalonamiento de ese espacio, que implica la autosimilaridad en encajamiento y la conexión de diferentes escalas en un único y mismo contexto. La gradación que permite el paso de lo local a lo global es un elemento primordial de la obra de Serres. Para Olson (1966), hace parte integrante de la topología que solo puede explicar el "talento de Melville para revelar lo infinitamente grande por medio de lo infi- 
nitamente pequeño" (p. 49). La potencia de la frente de la ballena, por ejemplo, resulta de un escalonamiento, de una interconexión entre el aire "impalpable" de los pulmones, la elasticidad de la envoltura frontal y la fluidez de su movimiento.

Con el prisma de Serres, las figuras de estilo de Moby-Dick se leen como un conjunto de operaciones topológicas. Muchos tropos e imágenes pueden ser reducidas a la operación topológica llamada "transformación del panadero". Como su nombre lo indica, la transformación del panadero se apodera de un espacio y lo estira en un sentido, lo contrae en otro, lo repliega sobre sí mismo. Este amasado encuentra una ilustración en el capítulo intitulado "Un apretón de manos", en el que Ismael explica que el esperma del cachalote, una vez enfriado, se condensa en terrones a los que hay que devolver su fluidez deshaciéndolos. Igual que la transformación del panadero modifica sin cesar la topología de una forma, el amasado de Ismael implica el paso del estado sólido al estado líquido. El cuerpo humano también se transforma al punto que las manos de Ismael terminan por trazar los arabescos de las topologías continuas. "Después de tener las manos metidas unos pocos minutos, mis dedos parecían como anguilas y empezaron por decirlo así, a serpentear y a hacer espirales" (Melville, 1978, p. 234). Las figuras serpentinescas y espiralazas que evoca esta imagen, remiten a lo que Olson llama "los espacios elípticos e hiperbólicos" de Melville (Olson, 1966, p. 50).

En la topología compleja del espacio melvillano, la "fuerza" más enigmática, la más dinámica y la más formidable es el propio Moby-Dick, el cachalote. Muchas de sus descripciones expresan la continuidad de ese espacio. Presencia la más autónoma en el océano, Moby-Dick lleva la fluidez al extremo, al mismo tiempo que está inmerso en ese elemento fluido y englobador. Ismael reporta cómo "su abrumadora joroba, deslizándose por el mar como una cosa aislada, y envuelta continuamente en un anillo giratorio de la espuma más fina, como vellón verdoso" (Melville, 1978, p. 392). Aquí las distinciones espaciales se borran; el cachalote está a la vez por encima y por debajo de la superficie, sus contornos en círculo de un anillo de ecúmeno cuya textura reproduce los alvéolos interiores de la joroba. Suscita en su estela un concierto de fuerzas, de tintes y figuras: "Tenía ante sus ojos (...), la centelleante sombra blanca de su ancha frente lechosa, y una ondulación musical que acompañaba juguetonamente a la sombra; y por detrás, las aguas azules fluían intercambiándose entre el valle móvil de su firme estela; y a un lado y a otro, claras burbujas surgían y danzaban junto a ella" (Melville, 1978, p. 75); a la manera de Serres, podemos descomponer esta descripción siguiendo sus marcadores preposicionales y hacer aparecer un movimiento de vaivén: "ante" y "detrás" hacen eco a "acompañaba" e "intercambiándose"; la dinámica sintáctica de Melville transforma la descripción de la ballena en una evocación del medium que la envuelve: cachalote y océano se funden el uno en el otro. 
La armonía de los elementos se destaca del fondo de la turbulencia. Esta combinación de resonancia y turbulencia remite una vez más a una gradación; la teoría del caos estableció que la turbulencia de los fluidos contenía una serie iterativa de torbellinos. Por ejemplo, las aguas agitadas por el formidable cachalote implican un orden interno complejo y una economía de fuerzas. Esta forma de turbulencia es una imagen a la que Michel Serres le tiene afecto, pues significa un desorden que abriga una forma de orden diferente. Si se traduce la imagenería de Melville al lenguaje de Serres, la descripción de Moby-Dick recuerda la de Venus saliendo de las aguas, la "Venus turbulenta"6 que encarna la emergencia del orden (Venus como avatar de Eros) a partir del caos ${ }^{7}$.

Para Olson, las descripciones fisiológicas de Melville revelan nada menos que "el carácter y la estructura del sí (mismo) verdadero". La realidad fluctuante e intensiva está estructurada por una tensión entre movimiento y reposo. Melville reconcilia "el sentimiento o la necesidad de lo inerte (...), con las acciones más inmediatas y poderosas" (Olson, 1966, p. 51). A este respecto, un pasaje ejemplar es la evocación del movimiento de Moby-Dick en el agua: "una suave alegría, una poderosa suavidad de reposo con velocidad revestía a la ballena en su avance" (Melville, 1978, p. 392). Según Olson (1966), la textura de lo real está compuesta de un "campo de inercia flexible" (p. 52). La topología es indispensable para la comprensión de la naturaleza y las formas en ese medium, porque permite captar y describir formas fluidas, dinámicas, definidas no tanto por contornos distintos sino por una gradación. La topología aguza la percepción al mismo tiempo que conceptualiza los atributos espaciales de las formas percibidas; ellas nos permite "colarnos entre los tipos vagos de la morfología y las estructuras ideales de la geometría propiamente dicha" (Olson, 1966, p. 49).

\section{Topología de lo impalpable}

El uso que Serres hace de la topología tiene que ver con una física en la cual los discursos morfológicos alcanzan límites reveladores del carácter esencialmente informe u opaco del mundo. En esta metafísica epicúrea el mundo no tiene "fondo" ni fundamento, porque el "clinamen opera la primera codificación"; bajo las fundaciones, el suelo está siempre a punto de desplomarse, la estabilidad temporal del torbellino brota de una turbulencia primera. Incluso cuando la gradación sugiere una nueva manera de percibir el orden espacial y la forma, hay allí algo de infundado o de impalpable. El movimiento gradual hacia lo bajo siguiendo un proceso recursivo de borradura, nos hace penetrar en un reino

\footnotetext{
6 Esta fórmula retomada en la cuarta tapa de Génesis, ha sido estudiada por Marís Assad, que hace ella misma eco a Olson y Melville cuando define la metáfora de la génesis/caos como "ese tumulto caótico que es el mantillo, el plasma de los momentos estocásticos de la invención".

7 Para un estudio detallado de esta metáfora en Serres, ver María L. Assad, "Michel Serres: In search of a tropography".
} 
de polvos imperceptibles. Ocurre así con la operación iterativa que genera una serie de Cantor: tomad un segmento, cortad el tercio de la mitad, luego cortad el tercio de la mitad de cada nuevo segmento ad infinitum.

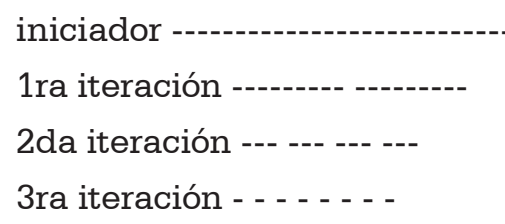

Ahora bien, esta operación no puede proseguirse indefinidamente; conduce fatalmente a la disolución de toda forma espacial. Tal es la tesis propuesta por Brian Rotman en Ad infinitum: una "matemática corporalizada" requiere "una concepción radicalmente nueva de la iteración (que) reemplace la repetición sin fin de la imagen ortodoxa, la iteración de lo mismo, por un diminuendo entrópico" (Rotman, 1993, pp. 10-11). En lugar de sugerir una autosimilaridad que se extienda indefinidamente hacia abajo, los componentes implicados en la operación iterativa "se desvanecen y tienden hacia la indeterminación a medida que se los enumera. Esta indeterminación se emparienta más con nuestra experiencia de la iteración de lo que lo haría una infinidad misteriosamente trascendental" (Rotman, 19993, pp. 10-11).

Para regresar al universo fluido de Serres-Olson-Melville, podríamos decir que si la topología hace aparecer formas complejas en un medio flexible, la fluidez misma del medio difumina los contornos y nos deja a la deriva. La topología y la física del mundo terminan por perderse en un reino metafísico y místico. La ecología tropieza con sus propios límites, más allá de los cuales se extienden caminos que nos conducen al animismo o al silencio, a una distancia respetuosa. El paso de la fisicalidad al misticismo se expresa en Melville en el capítulo titulado "La blancura del cachalote", donde la blancura aparece como un signo irreductiblemente plural, a la vez cualidad corporal y significante extraño que apunta hacia el vacío. Así mismo, las últimas descripciones de Moby-Dick confieren a su imponente presencia física una cualidad nebulosa. En el último día de cacería, el cachalote emerge de las aguas de una manera mucho más caótica: "de pronto el agua que los rodeaba empezó a hincharse lentamente y luego se elevó de golpe, como apartándose de un iceberg sumergido que ascendiera a toda velocidad hacia la superficie (...), una forma inmensa, arrastrando cabos y arpones y lanzas salió como un balazo de abajo del agua" (Melville, 1978, p. 419). El movimiento abrupto y tangente del cachalote señala su próxima desaparición.

Forma imponente en medio de las profundidades amorfas del océano, Moby-Dick termina por desvanecerse en una traza impalpable: "envuelta en un leve velo de niebla que caía, se cernió por un momento en el aire irisado, y 
luego cayó atrás, hundiéndose en lo profundo" (Melville, año, p. 88). La bruma, última huella visible que el cachalote deja tras de sí, evoca su naturaleza por siempre misteriosa. En el capítulo la "Fuente", Ismael constata que cuando "su parte central está oculta en la niebla nívea y resplandeciente que la envuelve, y ¿Cómo podéis decir con seguridad si cae de ella alguna agua (...)? ¿Cómo sabéis que no son simples condensaciones de su vapor?". Ismael por su parte emite la hipótesis de que "ese soplo es una pura neblina" (Melville, año, p. 60). Los contornos de la ballena y su soplido se vuelven de repente nebulosos humos. Esta imagen despierta en Ismael "las espesas brumas de las dudas que entenebrecen mi cerebro". Más allá de la superficie compleja de la escritura de Serres, se reencuentra ese mismo escepticismo. Serres enfrenta la textura del mundo como una multiplicidad irreductible, siempre cambiante. Por naturaleza, lo múltiple "es quizás un poco viscoso" (Serres, 1992b). Como lo anota María Assad, esta afirmación "zapa la certidumbre del ser"; Serres hesita en efecto en afirmar ("quizás un poco") la menor realidad, incluso la de lo "múltiple" o de lo "viscoso" (p. 281). Una multiplicidad viscosa que estaría compuesta de una pura niebla.

El hecho de que lo real parezca tan elusivo, por no decir ilusorio, tiene que ver con el carácter transitorio de todas las "cosas" en el universo turbulento del continuo, las formas temporales de orden terminan por regresar al caos: "los torbellinos se deshacen (...), todos esos trastornos regresan al arroyo principal" (Serres, 1994, p. 161). La imagen de Serres le hace eco a la última visión de Pequod: "círculos concéntricos envolvieron a la propia lancha solitaria, y a todos sus tripulantes, y a todo remo flotante, y a toda asta de lanza; y haciendo girar todos, con cosas animadas e inanimadas, alrededor de un solo torbellino, se llevaron de la vista hasta la más pequeña astilla del Pequod" (Melville, 1978, p. 91). El torbellino que se traga al Pequod evoca el carácter autodestructor del capitán Ahab, así como el paso de esta vida a la otra (Ismael sobrevive aferrado al ataúd de Queequeg). Asimismo para Serres la disolución de los torbellinos es un "proceso natural", un momento del ciclo de la vida llevado por un flujo temporal antrópico.

\section{La vuelta del atlas}

Michel Serres reconfigura los discursos y los saberes, negocia transiciones y dispone aberturas en el tejido de la cultura para poder hacer su nicho en un paisaje adaptado a las condiciones cambiantes del mundo contemporáneo. Practica así la ecología cultural en el sentido etimológico del término (al venir ecología del griego oikos, casa). El interés creciente por la eco-crítica se sostiene en esta simplísima intuición, pero proveniente de factores complejos: en el momento en que la humanidad es una presencia dudosa en la biosfera, es 
hora de recordar que la tierra es nuestra casa y debe ser mantenida como tal. $\mathrm{El}$ discurso ecológico puede contribuir a su mantenimiento porque representa un lugar cultural donde desarrollo tecnológico, saber científico y vocación ética (es decir: espiritual) convergen en un haz de realidad, de placer y moralidad.

Tales lugares se encuentran frecuentemente en Atlas (1994), relato de viaje que explora espacios tanto virtuales como geográficos, con el fin de replegar juntos lo natural, lo textual y lo tecnológico. Adoptando aquí una postura más terrenal, Serres presenta una especie de resumen retrospectivo que reacomoda diversos segmentos de su obra. Pero las cartografías de Atlas incluyen también sitios inesperados: el último relato especialmente traza un viaje al Tibet vía Tintin, el abominable hombre de las nieves y el sueño de la mariposa de Tchuang-Tse. Este recorrido no es tanto una búsqueda espiritual new age en un budismo de tiras cómicas, como una expedición a través de la tundra buscando el monstruo de Frankenstein. Serres aspira sin embargo a una relación más fecunda entre el hombre y la máquina, entre lo carnal y lo numérico. Su Atlas incluye un "mapa de la ternura, verbo y adjetivo", en el cual busca estirar el espacio para avanzar hacia el próximo pliegue, un porvenir posible y viable.

En las últimas páginas de las "Ciudades invisibles" de Italo Calvino, Marco Polo hojea el atlas imperial de Kublai Khan, esperando encontrar allí "un escorzo abierto en mitad mismo de un paisaje incongruente, un aflorar de luces en la niebla, el diálogo de dos transeúntes que se encuentran en medio del trajín". A partir de esos elementos "juntaré pedazo a pedazo la ciudad perfecta, hecha de fragmentos mezclados con el resto, de instantes separados por intervalos, de señales que uno manda y no sabe quién las recibe" (Calvino, 1985, p. 174). En respuesta a la visión entrópica de Khan, para el cual "el último fondeadero no puede ser sino la ciudad infernal", Marco Polo formula un nuevo credo:

Dos maneras hay de no sufrir [el infierno]. La primera es fácil para muchos: aceptar el infierno y volverse parte de él hasta el punto de no verlo más. La segunda es peligrosa y exige atención y aprendizaje continuos: buscar y saber reconocer quién y qué, en medio del infierno, no es infierno, y hacerlo durar, y darle espacio (Calvino, 1985, p. 175).

Michel Serres que comparte la visión de Calvino, su amigo de larga data, siempre ha obrado por el mantenimiento de los valores contra la estrechez de espíritu del saber institucional. Combinando una cultura clásica y una receptividad a las tendencias más contemporáneas, nos entrega los instrumentos necesarios para encontrar y preservar esas diferencias que constituyen toda la diferencia. 


\section{Referencias}

Bateson, G. (1990). El espíritu y la naturaleza. Barcelona: Amorrortu.

Bateson, G. (1991). Counscious purpose versus nature. En G. Bateson, Pasos hacia una ecología de la menta. Buenos Aires: Lohlé-Planeta.

Batt, N. (1994). "L'Entre-Deux", A bridging concept for Literature, Philosophy and Science. SubStance, XXIII(74), 38-48.

Calvino, I. (1985). Las Ciudades invisibles. Barcelona: Minotauro.

Livingston, P. (1988). Literary knowledge: Humanistic inquiry and the philosophy of science, Cornell University Press.

Melville, H. (1978). Moby-Dick o la ballena. México: Universidad Autónoma.

Olson, C. (1966). Equal, that is, to the real itself. En R. Creeley (ed.), Selected Writings. New York: New Directions.

Olson, C. (1974). The present is prologue. En F. George, Additional prose: A bibliography on America, Proprioception, and other essays. California: Four seasons foundation.

Rotman, B. (1993). Ad infinitum: the Ghost in Turing's machine. California: Stanford University press.

Serres, M. (1977). Hermès IV: La Distribution. Paris: Minuit.

Serres, M. (1980). Le parasite. París: Grasset.

Serres, M. (1981). Discurso y recorrido. En C. Lévi-Strauss (dir.) Seminario sobre la Identidad. Barcelona: Petrel.

Serres, M. (1982). Genese. París: Grasset. (trad. L. A. Paláu, Medellín, 1992).

Serres, M. (1989). Literature and the exact science. SubStancia, 59, 3-34.

Serres, M. (1991). Hermes V, el Paso del noroeste. Madrid: Debate.

Serres, M. (1991). Le Tiers-instruit. París: F. Bourin. (El tercero instruido, trad. L. A. Paláu. Medellín, Septiembre de 1997).

Serres, M. (1994). El nacimiento de la física en el texto de Lucrecio. Valencia: Pre-textos.

Serres M. (1995). Atlas. Madrid: Cátedra.

Serres, M. (2004). El contrato natural. Valencia: Pre-textos.

Serres, M. (2010). Eclaircissements: cinq entretiens avec Bruno Latour (Aclaraciones tr. Luis Alfonso Paláu, Medellín, 1997 - Marzo de 2010).

Stefanovska, M. (1992). Reseña de El contrato natural. SubStance, XXI(67). 